\title{
The Temperature of the Bathtub Water in Space and Time
}

\author{
Lei Yu \\ ${ }^{1}$ School of North China Electric Power University, Baoding 071003, China \\ 3023961035@qq.com
}

Keywords: the heat conduction equation, the bathtub water, the PDE.

\begin{abstract}
In order to find the temperature of the bathtub water in space and time,we used the first law of thermo dynamicsFouriers Law and Calorie formula to derive the heat conduction equation and to study the temperature of the bathtub water in space and time. Firstly, We do not change time but change space to study the temperature distribution equation by simplifying the 3D model into a two-dimensional model Then we use the PDE toolbox of MATLAB for solving the equations . Finally, We only change the time to learn about the trend of temperature changes through the simulation tool of MATLAB
\end{abstract}

\section{Introduction}

China's total freshwater resources ranked the forefront of the world, but the per capita water resources is very small, so water conservation for us is very necessary, but in our daily life, we have a huge water consumption, mostly from the water temperature Conditioning, such as water is too hot or too cold are caused by excessive water waste, so the study of bath water temperature changes with time and space is necessary for the future of intelligent equipment, automatic water supply to provide a great help.

\section{Organization of the Text}

In order to study the temperature of the bathtub water in space and time, we use Fourier's Law and Calorie formula,the first law of thermo dynamics for creating a model.

Table 1: Notations and Descriptions

\begin{tabular}{ll}
\hline Notatio & Descriptions \\
\hline Tin & The temperature in the bathtub \\
Tout & The temperature in the bathroom \\
$T_{0}$ & The temperature of hot water flowing out of the \\
\multicolumn{1}{c}{ tap } & Specific heat capacity \\
$\rho$ & The dendity of the water \\
\hline
\end{tabular}

- Fourier’s Law

$$
d Q=-k(\mathrm{x}, \mathrm{y}, \mathrm{z}) \frac{\partial x}{\partial y} d S d t
$$

$k(x, y, z)$--- the thermal transmissivity of material

- $\quad$ Calorie formula

c--- the specific heat capacity

$$
Q=c m u
$$

$m$--- quality. 
- the first law of thermodynamics

$$
Q=Q_{1}+Q_{2}
$$

Q--- the heat absorbed by temperature change

Q1--- the heat flowing through the boundary

Q2--- the heat provided of heat reservior

Finally, we derive the heat conduction equation as follows

$$
\int_{t_{1}}^{t_{2}}\left[\iiint_{\Omega} c \rho \frac{\partial u}{\partial t} d V\right] d t=\int_{t_{1}}^{t_{2}}\left[\iiint_{\Omega}\left(\frac{\partial}{\partial x}\left(\mathrm{k} \frac{\partial u}{\partial x}\right)+\frac{\partial}{\partial y}\left(\mathrm{k} \frac{\partial u}{\partial y}\right)+\frac{\partial}{\partial z}\left(\mathrm{k} \frac{\partial u}{\partial z}\right)\right) d V\right] d t
$$

To simplified model, the temperature distribution equation is projected to the three plane[1] X-Y plane, Y-Z plane and X-Z plane.

- The temperature distribution equation on $\mathrm{X}-\mathrm{Y}$ plane

$$
\frac{\partial u}{\partial t}-k^{2}\left(\frac{\partial^{2} u}{\partial x^{2}}+\frac{\partial^{2} u}{\partial y^{2}}\right)=f(x, y, z)
$$

Boundary Conditions

$$
\left\{\begin{array}{l}
\frac{\partial u}{\partial x}+\frac{\partial u}{\partial y}+\left.h T\right|_{w}=h T_{\text {out }} \\
\frac{\partial u}{\partial x}+\left.h T\right|_{x= \pm \frac{b}{2},-\frac{a}{2} \leq y \leq \frac{a}{2}}=h T_{\text {out }} \\
\frac{\partial u}{\partial y}+\left.h T\right|_{y= \pm \frac{a}{2},-\frac{b}{2} \leq x \leq \frac{b}{2}}=h T_{\text {out }}
\end{array}\right.
$$

- The temperature distribution equation on Y-Z plane

$$
\frac{\partial u}{\partial t}-k^{2}\left(\frac{\partial^{2} u}{\partial y^{2}}+\frac{\partial^{2} u}{\partial z^{2}}\right)=f(x, y, z)
$$

Boundary Conditions

$$
\left\{\begin{array}{l}
\frac{\partial u}{\partial y}+\frac{\partial u}{\partial z}+\left.h T\right|_{w}=h T_{\text {out }} \\
\frac{\partial u}{\partial y}+\left.h T\right|_{y= \pm \frac{c}{2},-\frac{b}{2} \leq z \leq \frac{b}{2}}=h T_{\text {out }} \\
\frac{\partial u}{\partial z}+\left.h T\right|_{z= \pm \frac{b}{2},-\frac{c}{2} \leq x \leq \frac{c}{2}}=h T_{\text {out }}
\end{array}\right.
$$

- The temperature distribution equation on X-Z plane 


$$
\frac{\partial u}{\partial t}-k^{2}\left(\frac{\partial^{2} u}{\partial x^{2}}+\frac{\partial^{2} u}{\partial z^{2}}\right)=f(x, y, z)
$$

Boundary Conditions

$$
\left\{\begin{array}{l}
\frac{\partial u}{\partial x}+\frac{\partial u}{\partial z}+\left.h T\right|_{w}=h T_{\text {out }} \\
\frac{\partial u}{\partial x}+\left.h T\right|_{x= \pm \frac{c}{2},-\frac{a}{2} \leq z \leq \frac{a}{2}}=h T_{\text {out }} \\
\frac{\partial u}{\partial z}+\left.h T\right|_{z= \pm \frac{a}{2},-\frac{c}{2} \leq x \leq \frac{c}{2}}=h T_{\text {out }}
\end{array}\right.
$$

If we want to keep the temperature $\left(T_{\text {in }}\right)$ even throughout the bathtub, we should know the relationship between the temperature of the bathtub in space and $T_{i n}$, namely the relationship between $\sigma^{2}(H)$ and $T_{\text {in }}$

The temperature distribution of different $T_{\text {in }}$
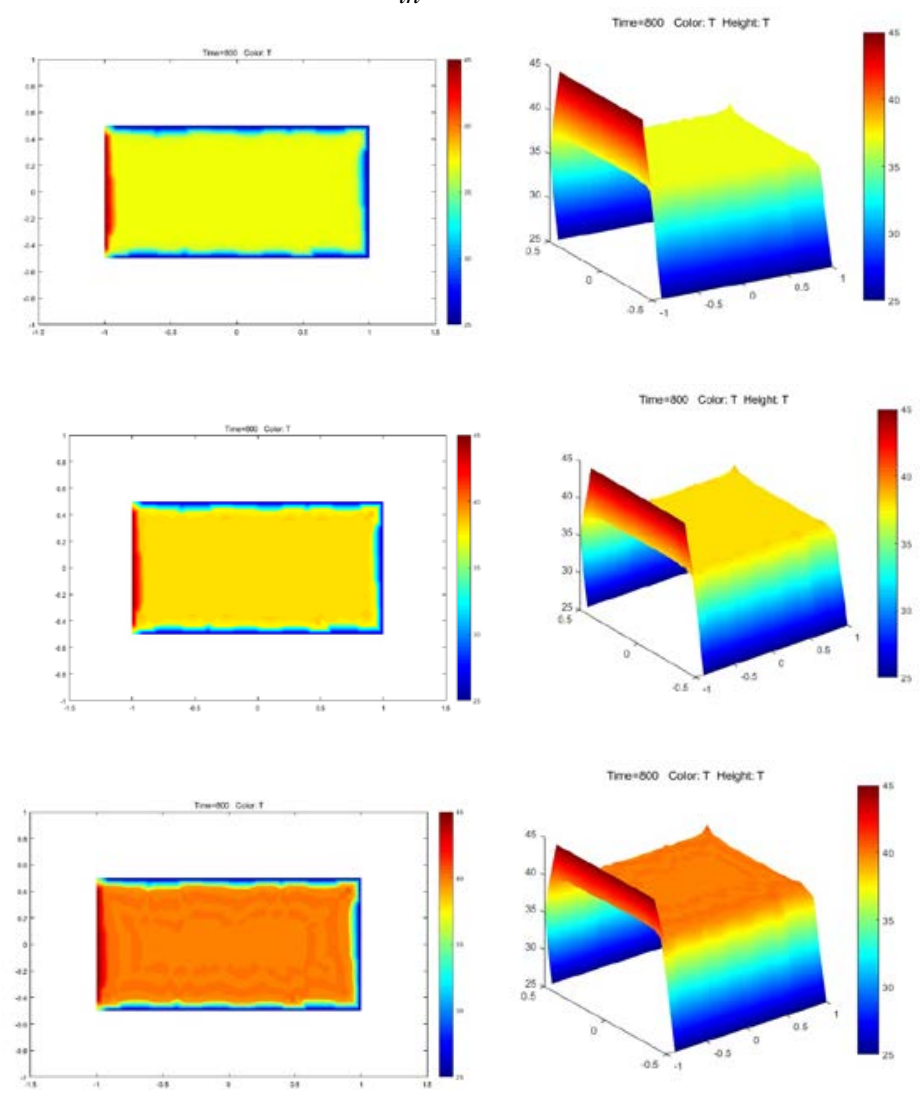

Figure 1: the temperature distribution of different $T_{\text {in }}$

\begin{tabular}{|c|c|c|c|c|c|c|}
\multicolumn{7}{|c|}{ Table 2: $\sigma^{2}(T)-T_{\text {in }}$} \\
\hline Tin & 37 & 38 & 40 & 42 & 43 & 44 \\
\hline$\sigma^{2}(T)$ & 0.850848987 & 0.931503596 & 1.060011382 & 2.343273425 & 2.876997834 & 3.001693311 \\
\hline
\end{tabular}

The relationship of $\sigma 2(\mathrm{~T})$ and Tin shows as Table 2 , we can easilly find that the $\sigma 2(\mathrm{~T})-\mathrm{Tin}$ function is an increasing function.The bigger Tin is the more difficult the temperature distribution evenness.

To find the temperature of the bathtub in time, we set Tin as a constant, based on the above analysis, We choose a middle temperature : $T_{i n}=40{ }^{\circ} \mathrm{C}$, in order to maximize even distribution of heat for the bathtub. 
Table 3: $\sigma^{2}(T), \bar{T}$ and $t$ relationship

\begin{tabular}{|c|c|c|c|c|}
\hline$t$ & 200 & 400 & 700 & 1000 \\
\hline $\bar{T}$ & 39.99280973 & 39.96742288 & 39.93929502 & 39.94171492 \\
\hline$\sigma^{2}(T)$ & 0.005386366 & 0.007572026 & 0.021716671 & 0.141813188 \\
\hline
\end{tabular}

In Table 3, we can find that under certain time scope and temperature terms both the variance of the temperature and the variance variation are very small, the temperature distribution of the bathtub basically doesn’t vary with time.

\section{Conclusions}

From the above analysis,we can know that the bigger $T_{i n}$ is the more difficult the temperature distribution evenness. Moreover, under certain time scope and temperature terms both the variance of the temperature and the variance variation are very small. Therefore,within the permissible error range, the temperature distribution does not change over time.

\section{References}

[1] ShengWei Yu. matlab mathematical modeling classic case of actual combat BeiJing Tsinghua University Press 2014.

[2] http://wenku.baidu.com/view/05a8a011866fb84ae45c8de6.h/

[3] http://baike.haosou.com/doc/2531035.html/

[4] http://wenku.baidu.com/view/9a2c5fcd050876323112129b.h/

[5] http://wenku.baidu.com/view/b90f7aee19e8b8f67c1cb98a.html/ 